Abramson countered that while reminder ads are a problem, the mention of risks is a "decoy" - "there are words about risk" but the appeal is emotional and aimed at expanding sales, Abramson said. - Ann Silversides, Toronto, Ont.

DOI:I0.I503/cmaj.080442

Affidavits for all the parties to the court challenge can be found at the website of Women and Health Protection, part of the coalition that received intervenor status. (http://www.whp-apsf.ca/en/documents /doc_index2.html\#charter)

\section{Ditch that white coat}

$\mathrm{S}$ ome British physicians call it "chasing sound bites." Others say the new "bare below the elbows" policy is simply good infection control. Whatever the opinion, few issues have generated controversy quite like the one that's ensued in the wake of the September 2007 dictum by the United Kingdom Department of Health (www.dh.gov.uk) to curb health care-associated infections in hospitals through such measures as clothing guidelines and isolation of infected patients.

The new rules obligate doctors to adopt a "bare below the elbows" dress code, that is, short sleeves, no wrist watch, no jewellery and avoidance of neckties when carrying out clinical activity. The traditional doctor's white coat is not just passé, it's not allowed. The Department of Health also hopes the new clothing guidance, which took effect in January, will prompt more hand and wrist washing.

It is difficult to ascertain the role of clothing in the spread of hospital infection. A group from Thames Valley University, London, UK, reviewed the evidence for the extent to which health care uniforms become contaminated with microorganisms, and their role in infection transmission, but there was limited evidence available $(J$ Hosp Infect 2007;66:30I-7).

Jonathan Fielden, Chairman of the British Medical Association Consultants Committee, sums up the feelings of the profession by saying that while all doc- tors support the cause, "there is a feeling that the government is chasing sound bites with its bare below the elbow and deep-cleaning policies, particularly given the lack of evidence that this aids reduction in the spread of infection. Nevertheless, most doctors are showing a willingness to implement the measures needed to reduce the scourge of hospital-acquired infection."

"This cooperation is accompanied by a sense of frustration and irritation that the government is not addressing a range of other major issues to tackle hospital infection, such as high hospital bed occupancy, excess antibiotic use, lack of isolation facilities and the conflicting pressures of other policies, such as the accident and emergency waiting targets," he adds. "These have been raised by the British Medical Association at ministerial level and will have more lasting effects on this major concern to all our patients.

Some believe the dictum crosses a line. "My basic gripe is that the policy is a public relations exercise which is not based on science; indeed with religious embolism and dress being exempt, it appears to be presented as "scientific fact' influenced by religion," says one doctor, insisting on anonymity.

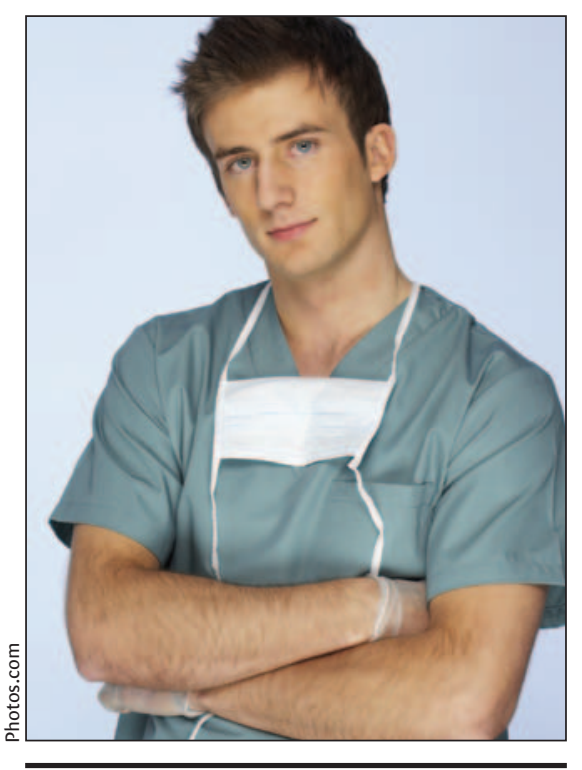

It's bare below the elbows from here on in for physicians in England as one of the symbols of the profession, the once-ubiquitous white coat, is outlawed as a health hazard.
Other doctors sounded a more positive note. Rohit Bazaz, Royal Free Hospital, London, UK, welcomes workwear guidelines. "Working on an infectious diseases ward, I am routinely expected to wear short-sleeved shirts and no wristwatch, and neckties are strongly discouraged." Bazaz favours an extension of the policy to include prohibitions on medical equipment like stethoscopes, which also can become infected with pathogenic microorganisms.

The Royal College of Physicians and the Infection Prevention Society are also supportive. "We have said that there is a need for clinical leadership on infection control issues. Although the evidence base on the details, for example, the impact of jewellery and watches is uncertain, nonetheless, complying with guidelines on appropriate measures sends out a message that doctors are taking the infection control message seriously in their daily practice," says Royal College of Physicians President Dr. Ian Gilmore.

The Infection Prevention Society was also generally supportive of the proposals. "The evidence for the effectiveness of these measures is limited but there is merit in enforcing a policy of short sleeves and no hand or wrist jewellery insofar as it facilitates effective hand hygiene," said Honourary Secretary Neil Wigglesworth. "The IPS [Infection Prevention Society] believes most infection prevention and control specialists share that view.

"Many health care organizations, including our own, had already put in place such a policy before the [Department of Health] guidelines were issued," Wigglesworth added.

As health is a devolved jurisdiction in the United Kingdom, the guidelines only apply to physicians in England.

Charles Saunders, chair of the Scottish Consultants Committee for Health Protection Scotland says a working group is looking at the issue of uniforms worn by all health care staff. A spokesperson with the British Medical Association in Scotland, who refused to be identified, said they are not aware of any plans to implement similar proposals to those of the Department of Health. — Cathel Kerr, Fife, Scotland

DOI:Io.I503/cmaj.080362 